\title{
A DANÇA NA EDUCAÇÃO FÍSICA: SABERES PROPOSTOS NA FORMAÇÃO INICIAL
}

\author{
Evando Carlos Moreira \\ Universidade Federal de Mato Grosso, Cuiabá, Mato Grosso, Brasil. \\ Elisangela Almeida Barbosa \\ Instituto Federal de Educação, Ciência e Tecnologia de Mato Grosso, Cuiabá, Mato Grosso, Brasil.
}

\begin{abstract}
Resumo
Este estudo teve como objetivo identificar os saberes relativos à Dança considerados importantes na formação do profissional em Educação Física no Estado de Mato Grosso, na opinião dos professores responsáveis pelo seu ensino. A pesquisa de abordagem qualitativa, do tipo descritiva, adotou como instrumento um questionário, respondido pelos professores responsáveis pelo ensino da Dança, delimitado aos cursos de Licenciatura que, ora aparece como conteúdo, ora como disciplina. Observamos que os professores entendem como importante que os acadêmicos conheçam e aprendam elementos que tornem a dança mais presente na escola, bem como seja mais valorizada pedagogicamente, a partir das vivências na sua formação.
\end{abstract}

Palavras-chave: Dança. Educação Física. Formação Profissional.

\section{Introdução}

As referências sobre Dança trazem abordagens sobre diversas perspectivas relacionadas à expressividade, comunicação, linguagem não verbal e cultura corporal ligadas à Educação Física. Com tanta diversificação, quando se fala do ensino da Dança na escola as pesquisas ainda relatam ausência ou dificuldade com o seu desenvolvimento nesse ambiente, geralmente com argumentos ligados ao pouco domínio do professor e/ou à formação inicial insuficiente para o trabalho pedagógico (MARQUES, 2007; BUOGO; LARA, 2011; EHRENBERG, 2014).

A formação profissional em Educação Física é regida por diretrizes que determinam que os conhecimentos ensinados devem estar orientados por valores sociais, morais, éticos e estéticos próprios de uma sociedade plural e democrática (BRASIL, 2004; BRASIL, 2015). Seguindo estes valores, a prática docente pode garantir o espaço da Dança, pois eles podem ser discutidos e representados pelo corpo na vivência, improvisação ou construção coreográfica, o que favorece o reconhecimento da importância desta manifestação cultural tão presente na sociedade. Ações nesse sentido também favorecem a aproximação dos acadêmicos, tanto daqueles que têm pouca vivência quanto os mais experientes, dos saberes que compõem o seu ensino na escola (EHRENBERG, 2014).

Em Mato Grosso não há cursos de formação profissional ou técnica em Dança. Dessa forma, pressupõe-se que aqueles que estão envolvidos neste segmento procuram a formação em Educação Física para acessar os conhecimentos científicos da área do movimento para ampliar seu trabalho como profissional. Além dos programas de ensino, muito "do que" e 
"como" é ensinado tem relação direta com a perspectiva pessoal e com a experiência de quem está ensinando (BARBOSA, 2011).

A partir dessa realidade, pontuando a configuração da Dança nos cursos de Educação Física em Mato Grosso e a subjetividade de seus atores, o que influencia diretamente nos saberes mediados com os acadêmicos e na sua condução na atuação profissional é que se insere o presente texto, tendo como objetivo identificar quais saberes relativos à Dança são considerados importantes na formação do profissional em Educação Física no Estado de Mato Grosso na opinião dos professores responsáveis pelo seu ensino.

\section{O Saber Docente}

A docência é uma atividade especializada responsável pela socialização dos saberes produzidos e acumulados pelas gerações: a profissão do professor, uma atividade autônoma e sistemática regida por regras construídas coletivamente e guiadas pelo processo de reflexão que deve ocorrer antes, durante e após o fazer didático, em que sua significação inclui, entre outros elementos, a necessidade dos professores construírem saberes e competências específicas do ofício, adquiridos por meio de formação acadêmica (NÓVOA, 1992).

Como reflexo ou consequência da formação acadêmica, o saber da profissão docente se constitui de conhecimentos, competências, habilidades e atitudes, o que Pimenta (2009) conceitua como saber, saber-fazer e saber-ser, não caracterizando a posição docente de maneira fortuita, pois ela reflete o que os próprios professores dizem a respeito de seus saberes pedagógicos, do conhecimento e da experiência.

É importante considerar outras características desse saber: ser plural, heterogêneo e temporal, composto por conhecimentos da formação profissional específica, por conhecimentos pedagógicos e também por conhecimentos disciplinares (sob forma de disciplinas), curriculares (objetivos, conteúdos e métodos) e experienciais (produzidos na atividade profissional) (TARDIF, 2012). A consolidação e a ampliação da relação entre esses saberes requer um processo de formação com saberes específicos, dada a singularidade de ensinar, que se articulem às dimensões da prática educativa para que o professor desenvolva sua prática pedagógica fundamentando-a em concepções de saber, de ensino e de aprendizagem.

Nesse sentido, é importante trabalhar com diversificação de propostas, modelos e práticas de formação, instituindo novas relações dos professores com o saber pedagógico e científico, experimentando novos modos de trabalho pedagógico e reflexão crítica sobre a sua utilização, o que favorecerá a sua apropriação pelos professores para mediar a relação ativa do aluno com os conteúdos, considerando os conhecimentos, a experiência, as potencialidades e os interesses (NÓVOA, 1992).

Nessas situações diversas, em decorrência dos desafios que se apresentam ao professor na configuração multifacetada das escolas atuais, a sua prática motiva a mobilização de diferentes saberes, dispondo de ferramentas que tornem o aprendizado mais efetivo. Assim, pensar uma formação que contribua para uma atuação dinâmica do professor requer analisar quais conhecimentos são fundamentais para o exercício desse profissional, refletindo sobre as habilidades necessárias para enfrentar as situações cotidianas do contexto educativo que podem fortalecer suas competências. É coerente buscar uma sólida formação teórico-prática alicerçada em saberes peculiares a esse processo, a fim de formar professores em concretas situações de ensino, oportunizando novas apropriações sobre o ensinar e o aprender na vivência da prática educativa em sua totalidade. 


\section{A Educação Física e O Ensino Da Dança}

Aliada à discussão dos saberes na formação profissional, a formação específica em Educação Física volta-se às diversas manifestações da cultura corporal, posicionando-se com saber didático-pedagógico para as intervenções, saberes técnico-funcionais aplicados, muitos deles sustentados por teorias e métodos voltados ao desempenho humano dentro das manifestações culturais, e saberes produzidos pela sociedade sobre o corpo e o movimento (MOREIRA, 2007).

Como parte das manifestações culturais presentes na sociedade, é importante compreender a presença significativa da Dança na educação, religião, identidade étnica, questões de gênero e organização política e social em muitas culturas (HANNA, 2008), com elementos que estimulam atitudes críticas que podem ser construídas a partir da percepção, na Dança, da expressão histórica de uma sociedade, seus valores, cultura, leis, crenças, resistências e outras identidades.

Toda essa complexidade pode ser discutida ao trabalhar com outras áreas que ajudam a compreensão e fruição da Dança, como estética, música, história, sociologia, antropologia e crítica, anatomia, cinesiologia, e conteúdos específicos que só se aprendem fazendo e sentindo sem intermediação de palavras (MARQUES, 2007). Nessa proposta de relação sociocultural com o mundo, as ações e o pensamento orientam as intervenções no ensino da Dança inter-relacionando aspectos políticos, filosóficos e pedagógicos para uma educação mais crítica. O mesmo acontece com outras manifestações da cultura corporal na Educação Física.

Além da contribuição dos saberes disciplinares, a Dança e a Educação Física têm como um dos pontos em comum a relação direta com o corpo, com a vivência e o domínio do movimento. Sborquia (2014) traz diversas reflexões sobre conceitos e fundamentos teóricometodológicos, pontuando que o movimento humano se desenvolve no tempo (duração e estruturação temporal), no espaço (forma e amplitude) e dentro de um ritmo (término e recomeço). Laban (1978), em uma de suas obras clássicas, faz referência constante a pesquisas em Dança e, ao analisar o movimento humano, estabeleceu quatro fatores do movimento: tempo - velocidade das ações corporais; espaço - exploração das mudanças de planos, direções; peso - a energia ou força muscular na resistência ao peso influencia na tensão do movimento; e fluência - ações paradas, contínuas ou interrompidas sob controle do movimento. A relação entre esses fatores é essencial para que o corpo dance.

Essas questões complementam-se com a observação de Hanna (2008), segundo a qual, ao identificar que cada indivíduo tem seu potencial criativo e alguma habilidade que possa ser incentivada e estimulada, essa relação pode ajudar na descoberta das dimensões física, intelectual e emocional, influenciando a maneira de fazer, atuar e visualizar a Dança. Entende-se que isto se liga diretamente a Marques (2007), que destaca a importância de vivenciar a Dança em si por meio de repertórios, improvisação e composição coreográfica, superando a repetição de movimentos estereotipados e, como reforça Buogo e Lara (2011), a comemorações e festas escolares, instrumentalizando o conhecimento.

Ehrenberg (2014) também evidencia essa proposta de superar as "dancinhas copiadas", e enfatiza que na formação profissional é de suma importância que as aulas que preparam professores para atuarem nas escolas devem se aproximar mais da realidade escolar e das necessidades reais do futuro professor, entendendo o professor como criador de processos metodológicos que busquem facilitar a aprendizagem dos alunos. A prática docente, não restrita ao ensino de técnicas (o que no caso da Dança muitas vezes se faz presente), é uma atividade que mobiliza diversos saberes de orientação da atividade educativa, incorporados à formação profissional dos professores (TARDIF, 2012).

Nesse caso, a Dança deve ser contextualizada como uma forma de expressão corporal criada pelos sujeitos e para os sujeitos e "[...] como manifestação da cultura corporal 
que pode ser capaz de inserir o aluno no mundo em que vive de forma crítica, reconhecendose como agente de possível transformação" (EHRENBERG, 2014, p. 48), compreendida ao longo do tempo e vinculada ao seu contexto social, político, histórico e cultural e com a formação humana do sujeito (MARQUES, 2007).

Essas propostas para a Dança na educação confrontam uma abordagem tecnicista que prioriza a formalidade da execução, o que tem grande importância para cativar o indivíduo a entender e vivenciar a Dança expressando seu potencial, necessidades e interesses sem padrões ou comparações, valorizando o conhecimento e a liberdade de criação, importante para professores em formação.

\section{Procedimentos Metodológicos}

A pesquisa se caracteriza como qualitativa do tipo descritiva, delimitando um grupo ou população com características específicas, relacionando variáveis, levantando opiniões, atitudes ou crenças de um determinado grupo (GIL, 2007) no intuito de compreender os significados e os sentidos apresentados pelos entrevistados (RICHARDSON, 1999).

O universo delimitou-se aos cursos de Licenciatura em Educação Física do Estado de Mato Grosso: três cursos em instituições públicas, dois da esfera federal e um da esfera estadual; oito em instituições particulares na capital do Estado e em cidades do interior. Nessas instituições, há disciplinas específicas de Dança - Dança e Fundamentos da Dança - e correlatas identificadas como Atividades Rítmicas; Atividades Rítmicas e Expressivas; Atividades Rítmicas, Expressivas e Dança; Metodologia do Ensino das Atividades Rítmicas e Expressivas. Em duas das 11 instituições a Dança é trabalhada como disciplina abrangendo dois semestres.

Os sujeitos foram os professores responsáveis pelas disciplinas descritas, totalizando o número de 12 indivíduos, identificados por números. Um dos cursos oferece duas disciplinas ministradas por professores diferentes, para os quais adotamos a identificação por números e letras. Dos 12 indivíduos, nove são mulheres e três são homens, 11 com graduação em Educação Física e um com graduação em Dança. Dadas as dimensões do Estado de Mato Grosso, utilizou-se um questionário com dados avaliados de um piloto e do levantamento de trabalhos relacionados ao assunto. Com questões direcionadas aos saberes da Dança que estão propostos na formação do profissional licenciado em Educação Física, a questão específica sobre "saberes da Dança importantes na formação em Educação Física" foi escolhida para este trabalho, pois se entende que é um ponto de grande importância e que permite traçar um panorama da ótica dos professores de Dança nos cursos de Licenciatura em Educação Física.

Os dados foram analisados de maneira interpretativa, buscando na interpretação a obtenção de sentidos mais amplos (GIL, 2007). Trechos das respostas ou respostas completas dos professores foram transcritas fidedignamente no intuito de evidenciar a expressão dos sujeitos e evitar desvios de interpretação. Nesse caso, optou-se por organizar as respostas em categorias de codificação, que para Bogdan e Biklen (1994), constituem um meio de classificar os dados descritivos recolhidos, reforçando que:

É um sistema que percorre os seus dados na procura de regularidades e padrões bem como de tópicos presentes nos dados, pois à medida que se vai lendo, os dados repetem-se ou destacam-se certas palavras, frases, padrões de comportamento, formas dos sujeitos pensarem e acontecimentos (BOGDAN; BIKLEN, 1994, p. 221).

Para atender aos objetivos desse estudo e à proposta de análise, foram estipuladas as categorias a partir das respostas dos sujeitos que se aproximaram em suas definições e significados, entendendo que as mesmas orientam metodologicamente sem limitar as análises 
dos dados. O presente trabalho foi aprovado pelo Comitê de Ética da Universidade Federal de Mato Grosso sob a identificação 047/CEP-HUJM/2011.

\section{Análise e Discussão Dos Dados}

Os saberes da Dança apontados na pesquisa permitiram apresentar perspectivas, abordagens e valores atrelados a ela como manifestação corporal e cultural. As respostas dos professores foram muito diversificadas, o que permitiu perceber práticas mais aprofundadas e outras mais generalistas ligadas à configuração da Dança como conhecimento, disciplina e/ou conteúdo.

Em nove das 11 instituições a Dança faz parte dos conteúdos das disciplinas correlatas que possuem carga horária variando de 60 a 80 horas. Ser parte de uma disciplina é, muitas vezes, uma situação limitadora, pois o professor precisa se organizar para atender todos os conteúdos (dança, jogos, brincadeiras, rítmica, teatro, dentre outros), o que pode comprometer um aprendizado melhor construído do acadêmico de Educação Física, tornando o desenvolvimento dos conteúdos superficial e restrito.

As respostas foram categorizadas da seguinte maneira:

Quadro 1 - Categorias

\begin{tabular}{|c|c|}
\hline Categoria & Ocorrência \\
\hline Respostas gerais & 4 \\
\hline Formação integral & 1 \\
\hline Fundamentos e Vivências & 5 \\
\hline Saberes disciplinares & 5 \\
\hline Saberes da prática pedagógica & 3 \\
\hline
\end{tabular}

Fonte: Elaborado pelos autores, 2018. dos à Dança:

Abaixo, transcrevemos algumas respostas generalistas sobre os saberes direciona-

Os conhecimentos fundamentais. (Professor 1)

Conhecimento de ritmos, rodas e brinquedos cantados; consciência corporal; atividades rítmicas (possibilidades). (Professor 2)

Ritmos/ritmo, conhecimento musical e cultural. (Professor 4)

MUITOS. Em qualquer área de atuação que escolhermos trabalhar precisamos de um amplo conhecimento. Conhecimento este que não é adquirido em 1 ou 2 semestres, mas em anos de estudo. (Professor 9)

Com base nas respostas, não é de se estranhar que muitos acadêmicos, principalmente aqueles que não possuem experiência, tenham resistência e dificuldade em abordar a Dança no exercício da docência, alegando que a formação inicial não foi suficiente para capacitá-lo. Vagas concepções propagadas na problematização do conhecimento podem fragilizar as expectativas com o aprendizado no período da formação, e como afirmam Marques (2007), Buogo e Lara (2011) e Ehrenberg (2014), deixam também o conhecimento instrumentalizado e insuficiente para o trabalho pedagógico.

Com graduação em Dança, do Professor 9 era esperado um detalhamento maior, uma relação mais clara de seus saberes específicos de formação com a preparação profissional em Educação Física, estabelecendo uma ponte entre as duas áreas, contribuindo para a ampliação 
das perspectivas do desenvolvimento da Dança na Educação Física como área que possui conhecimentos específicos. A resposta, no entanto, foi generalista. É inegável que precisamos ampliar os estudos para o trabalho com qualquer conhecimento, mas entende-se que alguém que possui formação em Dança e ensina no curso de Educação Física poderia apresentar mais claramente caminhos que aproximassem a relação entre as áreas.

Neste sentido, outra categoria sugere uma formação integralizada do indivíduo:

A sua importância como forma de expressão e sua contribuição no desenvolvimento físico e social do indivíduo. O professor deve entender essa importância para posteriormente entender os conceitos e conteúdos básicos da Dança para que esta possa ser inserida em suas aulas, não visando o corpo como um objeto da dança e sim a dança como um meio de transformação do ser em sua totalidade. (Professor 3a)

O Professor 3a trabalha a Dança numa disciplina específica e traz abordagens mais abrangentes para a preparação do acadêmico. Apresenta questões que vão de encontro às discutidas por Marques (2007), Ehrenberg (2014) e Buogo e Lara (2011) quando criticam a instrumentalização do corpo para a Dança como objeto apenas executante de coreografias e repetições de movimento, as "dancinhas estereotipadas". Assim, se posiciona favorável a desmistificar o corpo, pontuando a Dança como forma de expressão e trazendo seus conceitos para conhecimento e discussão, o que torna o trato com a Dança mais amplo em seus conhecimentos e práticas.

Identifica-se aqui uma abordagem sociocultural, considerando a possibilidade de transformação do indivíduo, o que de acordo com Ehrenberg (2014), a partir de sua expressão, a manifestação da cultura corporal pode ser capaz de inserir o aluno no mundo em que vive de forma crítica, fazendo-o reconhecer-se como agente de transformação.

Algumas respostas fizeram referência predominantemente a fundamentos e vivências corporais:

É importante que o aluno tenha um conhecimento sobre a história da dança, como tudo começou entender o que é dança, seus fundamentos, consiga coreografar e improvisar vários ritmos e colocar em prática todas essas vivências no âmbito escolar. (Professor 3b)

[...] a compreensão e vivência do ritmo; qualidades do som e movimento (expressividade corporal) e saber contextualizar os ritmos e estilos de dança no espaço escolar de acordo com o nível e interesse dos alunos para que a mesma seja prazerosa. (Professor 5)

Domínio da teoria e prática, noções de ritmos, fundamentos técnicos da dança, história da dança. (Professor 7)

Características e fatores constituintes do movimento e do ritmo; Consciência, Esquema e Expressão Corporal; Entendimento sobre o conceito de coreografia, elementos que a constitui e recursos coreográficos; [...]. (Professor 8)

[...] vivenciar movimentos simples de vários ritmos que despertem o interesse do acadêmico em aprender; noções de mapeamento musical, criação de sequências coreográficas simples; a avaliação final consiste em pesquisar, desenvolver coletivamente e apresentar em público uma sequência coreográfica simples. (Professor 10) 
[...] ser inserido em trabalhos de prática curricular que o permitam vivenciar no corpo a função de professor e dançarino ao mesmo tempo, como mostras e festivais [...]. (Professor 11)

O trabalho com ritmo é fundamental para o entendimento do corpo na Dança. A relevância do ritmo está, como pontua Sborquia (2014), nas reflexões sobre conceitos e bases teórico-metodológicas em que o movimento humano se desenvolve no tempo, no espaço e dentro de um período que termina e se reinicia. O entendimento do ritmo e a identificação dos estilos de Dança podem deixar o estudante mais confortável em suas experimentações, com menos vergonha de se expressar, descobrindo as possibilidades e alcances do corpo na execução do movimento ao conferir suas características a ele.

Além do ritmo, sobre a qualidade do movimento, os fatores discutidos por Laban (1978) atendem até hoje o trabalho com a Dança em qualquer ambiente. A relação entre o peso, o espaço, o tempo e a fluência é primordial para que o corpo dance e essa relação leva o indivíduo a um melhor entendimento do seu corpo, da sua movimentação e da sua expressão no espaço. Com isso, estimula-se o potencial criativo do indivíduo na descoberta das dimensões física, intelectual e emocional, influenciando a maneira de fazer, atuar e visualizar a Dança (HANNA, 2008).

Para que o ritmo e a qualidade do movimento possam ampliar a noção de esquema e consciência corporal, pode se estabelecer um diálogo com saberes da Educação Física que estão na base do estudo do movimento: a anatomia e a cinesiologia. Nesse diálogo, o entendimento do corpo pode ser otimizado e facilitar ainda mais as noções de peso, tempo e fluência nas vivências corporais, levando-se em consideração, como apresentado por Moreira (2007), os saberes técnico-funcionais calcados nas teorias e métodos do desempenho humano dentro das manifestações culturais.

Os fundamentos, juntamente com outros saberes que levam à vivência da Dança, também se direcionam ao que Marques (2007) apresenta como conteúdos específicos, que só se aprendem fazendo e sentindo, sem intermediação de palavras, a partir de outras maneiras de compreender o mundo, passando por todas as experiências de estudar, criar e dançar uma coreografia. A importância dessa vivência está no entendimento das várias perspectivas da Dança, tornando mais claras as possibilidades em cada lugar ocupado como professor, dançarino, coreógrafo, dentre outros.

Saberes disciplinares foram citados em respostas anteriores, mas se apresentaram com mais evidência em outras passagens:

[...] Conhecimentos históricos, sociais e culturais; habilidades motoras específicas; funções, classificações e estilos; bem como os objetivos, conteúdos e estratégias de ensino da dança. (Professor 6)

[...] Relações entre a Educação Física, a corporeidade e a dança; Conceito, Origem, Evolução e Divisões da Dança; Compreensão da dança enquanto conteúdo a ser trabalhado no currículo escolar. Esses conhecimentos devem ser contextualizados nos aspectos teóricos e vivenciados na prática. (Professor 8)

[...] Precisa também, conhecer os diferentes gêneros de danças (origens históricas, sentidos culturais e elementos técnicos característicos), com destaque para danças regionais, tradicionais ou folclóricas [...]. (Professor 11)

Esses saberes resgatam a característica plural descrita por Tardif (2012), a qual envolve conhecimentos de diversas fontes. Isso se relaciona diretamente ao que Nóvoa (1992) pon- 
tua em relação à diversificação dos modelos e práticas de formação que instituem novas relações dos professores (e futuros professores) com o saber pedagógico e científico, experimentando uma reflexão crítica sobre a sua utilização, o que favorecerá a sua apropriação pelos professores para mobilizá-los no exercício da sua profissão. O professor da formação inicial é, aqui, o mediador da relação ativa do aluno com os conteúdos, considerando os conhecimentos, a experiência, as potencialidades e os interesses.

As danças regionais, tradicionais ou folclóricas, muito defendidas por Ehrenberg (2014) na formação profissional e, consequentemente, na escola, tem grande diversidade e abrangência em Mato Grosso. Essa abordagem reforça o que Hanna (2008) diz sobre a função educativa da Dança, abrindo espaço para discutir identidades étnicas e organização política e social em muitas culturas. Enxergar na Dança essas possibilidades é reconhecer seu sentido como atividade de significativo valor social, moral, ético e estético presente numa sociedade democrática (BRASIL, 2004; BRASIL, 2015), além da sua capacidade de agregar e perpetuar valores de uma cultura, conduzindo à compreensão dos saberes da própria cultura e outras manifestações.

Desta forma, transcrevemos abaixo a opinião de alguns professores sobre as referências aos saberes da prática pedagógica:

[...] são fundamentais os conhecimentos relativos aos aspectos pedagógicos da dança nas dimensões conceituais, procedimentais e atitudinais. (Professor 6)

[...] dimensões conceitual, procedimental e atitudinal do conteúdo Dança ou Atividades Rítmicas e Expressivas; discussões que envolvam a relação mídia e dança, processo de estilização da dança, preconceitos em relação a aprendizagem e prática da dança, possiblidades lúdicas do ensino da dança. (Professor 11)

[...] Ter clareza do papel e função pedagógica do ensino da Dança Escolar ao trabalhar com a formação do aluno, numa perspectiva includente. (Professor 11)

Os apontamentos desses professores remetem à ideia de Nóvoa (1992) de que a consolidação e a ampliação das relações entre saberes requer um processo de formação com saberes específicos articulados às dimensões da prática educativa, que levam ao saber, saber-fazer e saber-ser conceituados por Pimenta (2009). No caso da Educação Física, a formação específica deve atender às diversas manifestações da cultura corporal, configurando-se como saber didático-pedagógico para as intervenções. O professor desenvolve sua prática pedagógica fundamentando-a em concepções de saber, de ensino e de aprendizagem, considerando a singularidade e as demandas de todo o processo. É claro que um conhecimento mais aprofundado demanda tempo, experiência e muito estudo para um trabalho seguro e efetivo de ensino e aprendizagem, mas a formação inicial é o momento em que se tem os primeiros contatos com as fontes e referências de conhecimento que levarão à prática docente que, como pontua Tardif (2012), mobiliza diversos saberes de orientação da atividade educativa, que fornecem um arcabouço ideológico à profissão e algumas técnicas de saber-fazer. Técnicas essas que permitirão mais confiança para desenvolver a Dança na prática profissional.

Mesmo em disciplinas correlatas, a maioria dos professores demonstrou ter claramente definida uma abordagem da Dança para a formação inicial em Educação Física. É importante enxergar que o trabalho com o movimento deve se desenvolver numa perspectiva plural do saber, na realidade plural das instituições de ensino, dos indivíduos, fazendo com que a Dança 
seja vista num todo, presente na sociedade em manifestações de sentidos e simbologias diversificadas.

É fato que os professores da pesquisa se preocupam com elementos gerais da Dança na formação dos futuros professores de Educação Física, da teoria à prática, do saber constituído à vivência corporal, dos movimentos básicos à diversidade de ritmos e gêneros, da preparação pedagógica para a atuação profissional. Essas propostas têm grande valor na medida em que se voltam ao desenvolvimento físico, cultural, afetivo e social do indivíduo e não à sua especialização técnica, pois o objetivo não é formar profissionais da Dança. A intenção maior é munir o futuro professor de conhecimentos e metodologias que tornem mais efetiva a presença da Dança na escola, com os conhecimentos e valores que lhe cabem.

\section{Considerações Finais}

A resposta da maioria dos professores sugere estudo e dedicação ao desenvolvimento da Dança nos cursos de Educação Física. A diversidade de ideias e perspectivas não foi surpresa e como resultado foi significativo conhecer a preocupação em levar a Dança para a escola por meio de indivíduos profissionalmente preparados. Isso tem grande peso ao considerar que nas escolas de Mato Grosso a Dança chega (quando chega) às crianças e adolescentes como conteúdo das disciplinas de Artes e Educação Física, ou ainda, através de educadores vinculados a projetos extracurriculares.

As ideias se aproximaram em relação aos saberes importantes na formação inicial sobre Dança e, considerando a subjetividade da pergunta, não houve consenso nas opiniões. A falta de consenso criou pontos para reflexão, como a diversidade das Danças; diferenças geográficas dentro do próprio Estado; diferentes origens étnicas, culturais e religiosas; estas individualidades presentes devem ampliar as discussões sobre Dança na configuração da formação inicial em Educação Física.

Mesmo nas subjetividades, foi possível perceber em muitas expressões o embasamento teórico e a provável experiência do indivíduo prática (dançando) ou pedagógica (ensinando há algum tempo). A vivência da Dança é algo a se ressaltar, pois como foi citado por alguns sujeitos, é importante que os acadêmicos busquem vivências práticas como dançarinos e coreógrafos para fazer parte e entender todo o processo de criação e desenvolvimento do corpo na Dança, favorecendo a associação entre o artístico e o educativo para que o processo criativo e crítico não seja comprometido no decorrer do processo de ensino e aprendizagem.

A pluralidade dos saberes, trazida por Tardif (2012) e Pimenta (2009), atende melhor a realidade do ambiente escolar, os indivíduos em diferentes fases do desenvolvimento e as vivências que favoreçam a construção do conhecimento pela experiência corporal. Ao buscar experiências teórico-práticas diversas, o professor amplia as suas possibilidades de trabalho na escola a partir das vivências na formação inicial e abre espaço para maneiras diferenciadas de tornar a Dança acessível a todos, abordando as dimensões do ser humano pela vivência artística, lúdica, técnica, experimental do movimento.

A característica das disciplinas de carga horária maior ou menor não permite um trabalho tão amplo e aprofundado para a formação, mas também não impede que um indivíduo busque experiências que sirvam de base e referência para considerar efetivamente a Dança nas aulas de Educação Física. Os professores da formação inicial também podem buscar essas experiências acompanhando as mudanças de técnicas, fundamentos e abordagens pedagógicas. Mas tratando da prática docente, é importante que a Dança seja apresentada e desenvolvida como um saber da expressão e comunicação humana, como objeto de apreciação significativa e como produto cultural e histórico, de maneira que haja o entendimento de que ela faz parte e se pauta nos saberes que são construídos por indivíduos a todo tempo. 


\title{
DANCE IN PHYSICAL EDUCATION: PROPOSED KNOWLEDGE IN INITIAL TRAINING
}

\begin{abstract}
This study aimed to identify the knowledge about Dance considered important in the training of professionals in Physical Education in the State of Mato Grosso, Brazil, in the opinion of the teachers responsible for their teaching. The research of qualitative approach, of the descriptive type, adopted, as an instrument, a questionnaire, answered by the teachers responsible for the teaching of Dance, delimited to the degree courses, that sometimes appears as content, now as a discipline. We observe that teachers understand how important is for academics to know and learn elements that make dance more present in school, as well as being more pedagogically valued, based on the experiences in their formation.
\end{abstract}

Keywords: Dance. Physical Education. Professional Formation.

\section{DANZA EN EDUCACIÓN FÍSICA: CONOCIMIENTO OFRECEN DE FORMACIÓN INICIAL}

\section{Resumen}

Este estudio tuvo como objetivo identificar el conocimiento en la danza considera importante en la formación profesional en Educación Física en el Estado de Mato Grosso, en opinión de los profesores responsables de su educación. La investigación cualitativa, descriptiva, adoptado como instrumento de un cuestionario a los profesores que enseñan la danza, limitada a los cursos de grado que ahora aparece como contenido, o como disciplina. Hemos observado que los profesores entienden la importancia de que los estudiantes saben y aprender los elementos que conforman el más presente en el baile de la escuela, y se valorarán más pedagógicamente, de las experiencias en su formación.

Palavras clave: La danza. Educación Física. Formación profesional.

\section{Referências}

BARBOSA, Elisangela Almeida. A dança na formação de professores de educação física: saberes e conhecimentos na intervenção profissional. 2011. 160 f. Dissertação (Mestrado em Educação) - Instituto de Educação, Universidade Federal de Mato Grosso, Cuiabá, MT, 2011.

BOGDAN, Robert; BIKLEN, Sari. Investigação qualitativa em educação: uma introdução à teoria e aos métodos. Porto: Porto Editora, 1994.

BRASIL. Ministério da Educação. Conselho Nacional de Educação. Resolução nº 7, de 31 de março de 2004. Institui as Diretrizes Curriculares Nacionais para os cursos de graduação em Educação Física, em nível superior de graduação plena. Diário Oficial [da] República Federativa do Brasil, Poder Executivo, Brasília, DF, 5 jul. 2004, Seção 1, p. 18-19; Brasília, DF, 2015.

Ministério da Educação. Conselho Nacional de Educação. Resolução no 2, de 1 de julho de 2015. Define as Diretrizes Curriculares Nacionais para a formação inicial em nível superior (cursos de licenciatura, cursos de formação pedagógica para graduados e cursos de segunda licenciatura) e para a formação continuada. Diário Oficial [da] República Federa- 
tiva do Brasil, Poder Executivo, Brasília, DF, 2 jul. 2015, Seção 1, p. 8-12; Brasília, DF, 2015.

BUOGO, Edmara Cristina Bonetti; LARA, Larissa Michelle. Análise da dança como conteúdo estruturante da educação física nas diretrizes curriculares da educação básica do Paraná. Revista brasileira de ciências do esporte, Florianópolis, v. 33, n. 4, p. 873-888, out./dez. 2011.

EHRENBERG, Mônica Caldas. A dança nos cursos de licenciatura em Educação Física: diagnósticos e possibilidades. In: EHRENBERG, Mônica Caldas; FERNANDES, Rita de Cássia; BRATIFISCHE, Sandra Aparecida (Org.). Dança e educação física: diálogos possíveis. Várzea Paulista, SP: Fontoura, 2014.

GIL, Antonio Carlos. Métodos e técnicas de pesquisa social. 5. ed. São Paulo: Atlas, 2007.

HANNA, Judith Lynne. A nonverbal language for imagining and learning: dance education in K-12 curriculum. Educational Researcher, v. 37, n. 8, p. 491-506, 2008.

LABAN, Rudolf. Domínio do Movimento. São Paulo: Summus, 1978.

MARQUES, Isabel. Dançando na escola. 4. ed. São Paulo: Cortez, 2007.

MOREIRA, Evando Carlos. Contribuições dos programas de pós-graduação stricto sensu na formação e atuação dos docentes de ensino superior: o caso da educação física. 2007. 427 f. Tese (Doutorado em Educação Física) - Faculdade de Educação Física, Universidade Estadual de Campinas, Campinas, SP, 2007.

NÓVOA, António. Formação de professores e profissão docente. In: NÓVOA, António. (Coord.). Os professores e a sua formação. Instituto de Inovação Educacional. Lisboa: Publicações Dom Quixote, 1992.

PIMENTA, Selma Garrido. Formação de professores: identidade e saberes da docência. In: PIMENTA, Selma Garrido. (Org.). Saberes pedagógicos e atividade docente. 7. ed. São Paulo: Cortez, 2009.

RICHARDSON, R. J. Pesquisa social: métodos e técnicas. 3. ed. São Paulo: Atlas, 1999.

SBORQUIA, Silvia Pavesi. As manifestações rítmicas e expressivas: sentidos e significados na Educação Física. In: EHRENBERG, Mônica Caldas; FERNANDES, Rita de Cássia; BRATIFISCHE, Sandra Aparecida. (Org.). Dança e educação física: diálogos possíveis. Várzea Paulista, SP: Fontoura, 2014.

TARDIF, Maurice. Saberes docentes e formação profissional. 13. ed. Petrópolis, RJ: Vozes, 2012.

Recebido em: 22/02/2017

Revisado em: 30/08/2017

Aprovado em: 21/02/2018 
Endereço para correspondência:

ecmmoreira@uol.com.br

Evando Carlos Moreira

Universidade Federal de Mato Grosso,

Av. Fernando Corrêa da Costa, 2367

Boa Esperança, Cuiabá - MT, 78060-900 